\title{
Seasonal dependence of semidiurnal equatorial magnetic variation during quiet and disturbed periods
}

\author{
Akiko Fujimoto ${ }^{1, *}$, Akimasa Yoshikawa $^{2}$,Teiji Uozumi $^{2}$, and Shuji $\mathrm{Abe}^{2}$ \\ ${ }^{1}$ Kyushu Institute of Technology, Iizuka, Japan \\ ${ }^{2}$ International Center for Space Weather Science and Education, Kyushu University, Fukuoka, Japan
}

\begin{abstract}
The analysis of 20-year long-term semidiurnal lunar tidal variations gave the evidence that the semidiurnal variations are completely different between the magnetic quiet and disturbed periods. This is the first time that the seasonal dependence of disturbance-time semidiurnal variation has been provided from the analysis of the EE-index. We found the $K_{P}$ dependence of semidiurnal variation: For full and new moon phase, counter troughs are amplified during disturbance time, possibly related to disturbance dynamo. For all moon phase, there are positive enhancements in dawn and strong depressions after sunset, resulting from the penetration of polar electric filed. For Seasonal dependence, semidiurnal variations are divided to three seasonal groups, and characterized as deep trough, enhanced crest and weak structure for $\mathrm{D}$-solstice, Equinoxes and J-solstice, respectively. There is no significant longitudinal difference between Ancon and Davao, except for the amplitude of semidiurnal variations. The deep troughs occur during D-solstice and the enhanced crests during Equinoxes, at both Ancon and Davao.
\end{abstract}

\section{Introduction}

The semidiurnal variation is primarily caused by the motion of the moon, and often denoted as L. The equatorial L current variation is enhanced as Sq [1]. Recently, during Norther Hemisphere winter, the equatorial big $\mathrm{L}$ days are often related to the occurrence of stratospheric sudden warming events [2,3]. The role of lunar tidal magnetic variation involving SSWs have been reported by several researchers [4-9]. The semidiurnal lunar tidal magnetic variation, caused by L current system, can be a cause of the counter electrojet (CEJ), if the semidiurnal variation relatively large or daily Sq variation is weak. The occurrence of CEJs is mostly observed during few hours after dawn and before dusk and is rarely observed around local noon $[10,11]$. The quiet-time semidiurnal variation has been examined by many papers $[1,11,12-16]$, while the knowledge on the disturbance-time semidiurnal variability is limited owing to few report [17].

In term of space weather study, the CEJ magnetic variations is suggested to play an important role on the occurrence of Equatorial plasma bubbles (EPBs) [18,19]. The

\footnotetext{
* Corresponding author: fujimoto@ces.kyutech.ac.jp
} 
occurrence of EPBs has seasonal-longitudinal dependence [20]. In order to understand the CEJ effect for EPBs, we need to monitor the equatorial magnetic variation including the equatorial electrojet (EEJ) and CEJ through the both geomagnetic quiet and disturbance periods. The purpose of this work is to demonstrate comprehensively the seasonal variation of semidiurnal lunar tidal variation during both periods.

\section{Data and Methods}

We used the 1-minute resolution EUEL component of EE-index from January 1999 to December 2018 for the time-series analysis, to examine the modulations of equatorial semidiurnal magnetic field variations. EE-index was defined as described previously [21,22]. Briefly, EE-index is a ruler to monitor the equatorial geomagnetic field variation in real time and consists of two components: EDst and EUEL. EDst represents the global disturbance variation calculated as the average of the $\mathrm{H}$-components measured by several night-side magnetometers data. EUEL describes the local magnetic field variation which is given by the subtraction of EDst from the H-component. EUEL data at Ancon in Peru and Davao in Philippine were used in this work, to demonstrate the longitudinal dependence of semidiurnal variations (the coordinates of the observatories are listed in Table 1). The observation days in month is shown in Figure 1. The observation days were amount enough for each month, to discuss the seasonal dependence of semidiurnal variations. The 20-year long-term EUEL data covering almost two solar cycles (SC 23 and SC 24) allow us for the analysis on the minimum, maximum and intermediate stage of the solar activity.

The semidiurnal variations of EUEL $\left(E U E L_{S}\right)$ was derived by

$$
E U E L_{S}=E U E L_{3 h}-\overline{E U E L_{3 h, 91 \text { days }}}
$$

where $E U E L_{3 h}$ is the 3-hour running average of EUEL and $\overline{E U E L_{3 h, 91 \text { days }}}$ is the 91-daycentered average of $E U E L_{3 h} . E U E L_{3 h}$ was calculated to neglect of magnetic field disturbances with the frequency less than the frequency of DP2 (the DP2 is the magnetic effect of high-latitude current systems and their magnetic effects often extend toward the lower latitudes $[23,24])$. The assumption of the average days of $\overline{E U E L_{3 h, 91 \text { days }}}$ is reasonable to eliminate the luni-solar magnetic field effect [6]. The subtraction of formula (1) resulted in the semidiurnal lunar tidal variation.

All $E U E L_{S}$ data were sorted to by the solar local time and the moon age (= moon phase), into bins of $1 \mathrm{~h}$ in both local time (LT) and moon age. In this work, 1-minute $E U E L_{S}$ data were averaged to obtain $1 \mathrm{~h}$ values centered at 00:30 LT. $K_{P}$ index was referred to for the geomagnetic activity: the lower $K_{P}$ index is $K_{P} \leq 3$ for the quiet time and the higher $K_{P}$ index $K_{P} \geq 3+$ for the disturbance time. After this, $E U E L_{S}$ is referred to as "semidiurnal variation".

Table 1. Geographic and geomagnetic coordinates of the observatories used in the study.

\begin{tabular}{cccccc}
\hline $\begin{array}{c}\text { Station } \\
\text { name }\end{array}$ & $\begin{array}{c}\text { Geographic } \\
\text { latitude }\end{array}$ & $\begin{array}{c}\text { Geographic } \\
\text { longitude }\end{array}$ & $\begin{array}{c}\text { Geomagnetic } \\
\text { latitude }\end{array}$ & $\begin{array}{c}\text { Geomagnetic } \\
\text { longitude }\end{array}$ & $\begin{array}{c}\text { Dip } \\
\text { latitude }\end{array}$ \\
\hline Ancon & -11.77 & 282.85 & 0.77 & 354.33 & 0.82 \\
Davao & 7.00 & 125.40 & -1.02 & 196.54 & -0.84 \\
\hline
\end{tabular}



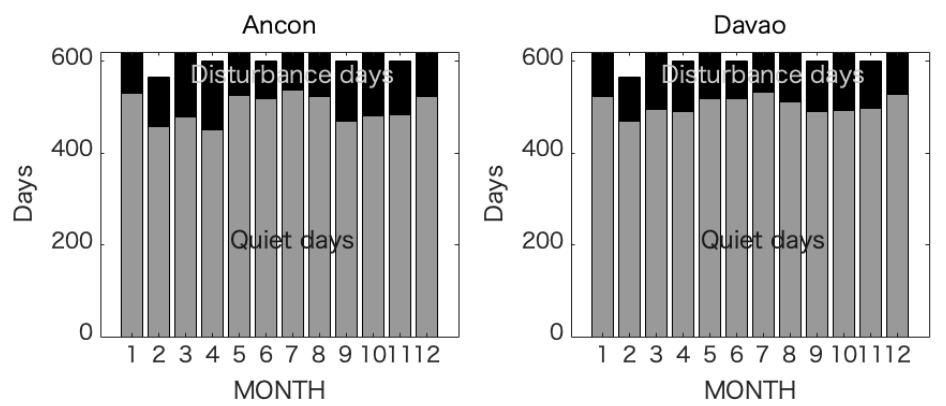

Fig. 1. Observational days in month for Ancon and Davao.

\section{Results}

We examined the dependence of $K_{P}$ index, season and longitude of observation site on the semidiurnal variation, to reveal the characteristic of semidiurnal variations during the magnetic disturbance periods.

\section{$3.1 \mathrm{~K}_{\mathrm{P}}$ dependence}

Figure 2 shows the comparison of averaged semidiurnal variations between the quiet and disturbance periods. Comparing between Figure 2 (b, e) and (c, f), the structure of semidiurnal variations is completely different between the quiet and disturbance periods. Except for the amplitude of semidiurnal variations, the same patter appears in both Ancon and Davao during the daytime (06:00-18:00 LT), for both magnetic activity conditions. In other words, the daytime pattern is roughly same between the quiet and disturbance periods, but the trough amplified and the crest became weak for the case of higher $K_{P}$. During the quiet time, the slight trough (blue color) exists before the morning sector (00:00-06:00 LT). The disturbance structure is opposite to the quiet time: the amplitude slightly increases in dawn sector and the decreasing in dusk sector.
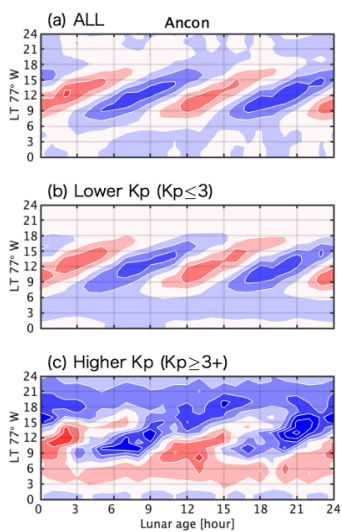
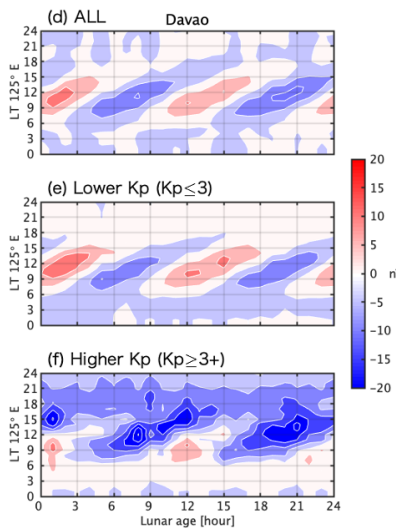

Fig. 2. Comparison of averaged semidiurnal variations between the quiet and disturbance periods. The lunar age is $0,12,6$ and 18 for the new moon, the full moon and the half moon, respectively. The red color and blue color indicate crest and trough of semidiurnal wave, respectively. 


\subsection{Seasonal/longitudinal dependence}

The seasonal variation is demonstrated in Figure 3 and 4 for Ancon and Davao, respectively. The seasonal dependence of semidiurnal variations is divided to three groups: D-solstice (December solstice is represented by the months November to February), J-solstice (June solstice by May to August) and Equinoxes (the combined equinoxes by the months March, April, September, October). From Figure 3-4 (a-1), semidiurnal variations are characterized as deep trough, enhanced crest and relative weak structure for D-solstice, Equinoxes and Jsolstice, respectively.

As shown in Figure 3-4 (m-o), the deep troughs occur for D-solstice and the enhanced crests for Equinoxes, at both Ancon and Davao during quiet time. For disturbance time in Figure 3-4 (p-r), the structure of semidiurnal variations is more complicate than the quiet time. There is no remarkable seasonal difference on the structure and amplitude of semidiurnal variation for each station.
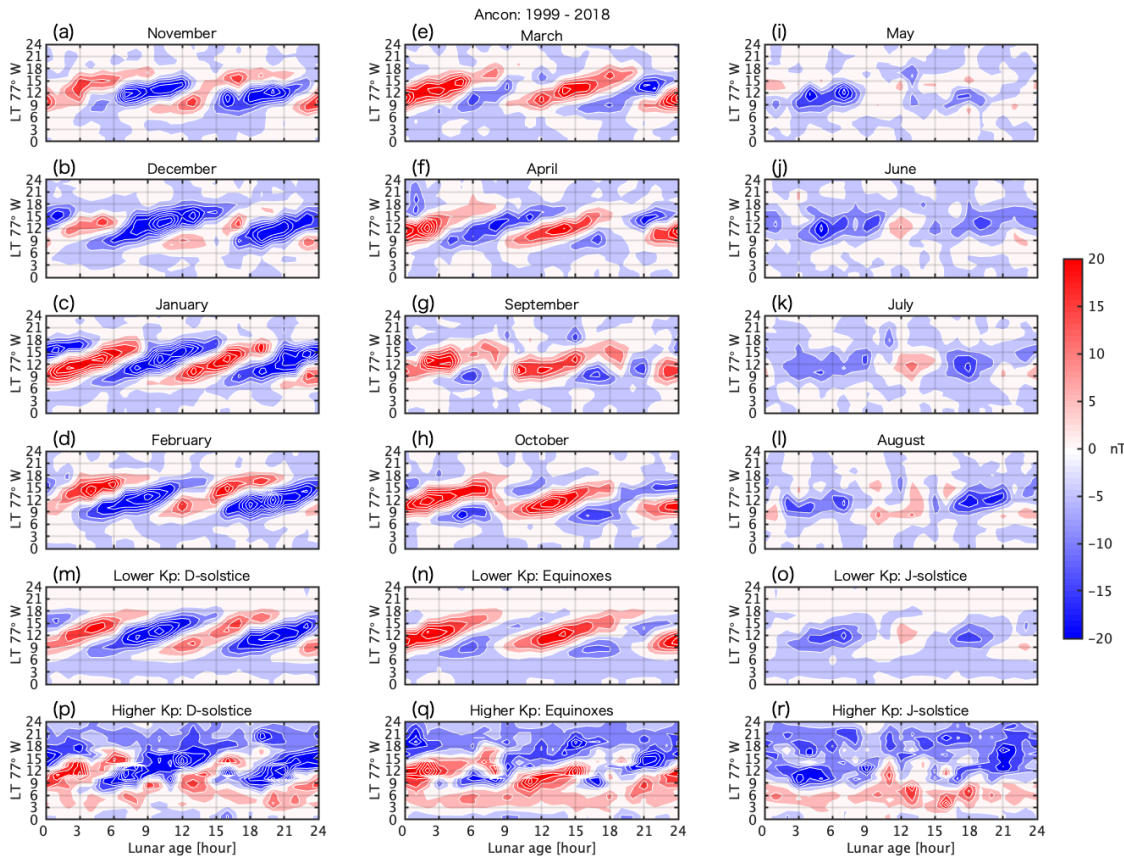

Fig. 3. Seasonal semidiurnal variation for Ancon. The upper 12 panel (a-1) shows monthly average of semidiurnal variation. (m-o) for lower $K_{P}$ and (p-r) for higher $K_{P}$. From left to right, each column responses to D-solstice, Equinoxes and J-solstice, respectively

\section{Discussion}

\section{1 $\mathrm{K}_{\mathrm{P}}$ dependence}

The semidiurnal lunar tidal variation can be a cause of the counter electrojet, if the semidiurnal variation relatively large or daily $\mathrm{Sq}$ variation is weak. During quiet time, the phase of the semidiurnal variation shifts to later local times according to the moon phase progresses. For the new and moon phases the counter trough remains in the afternoon [16]. The average structure of quiet-time semidiurnal variation as shown in Figure 2 is consists with the results of Rastogi (1973)[16]. 
During geomagnetic disturbances, the counter electrojet can be caused through the disturbance dynamo mechanism $[25,26]$. The eastward electric field produced by the normal quiet-time winds could be reduced by the effect of disturbance dynamo, and there is a reduced EEJ or CEJ during the storm recovery phase. [27; 17]. Besides, the counter electrojet is sometimes caused by the penetration of the polar-latitude electric field to equatorial latitudes [28-32].
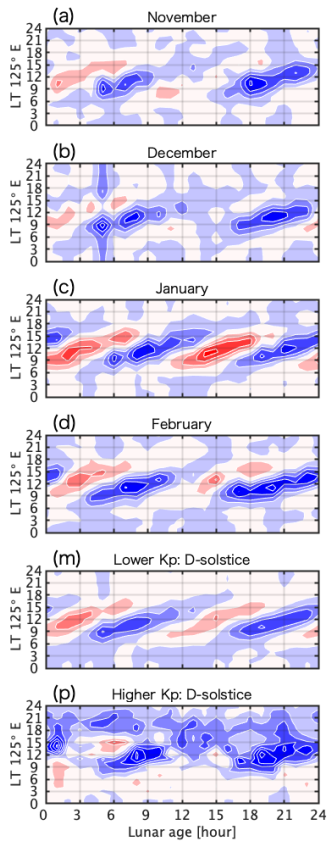
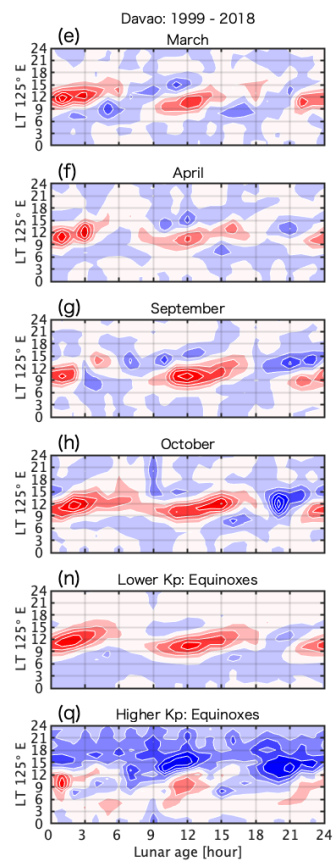
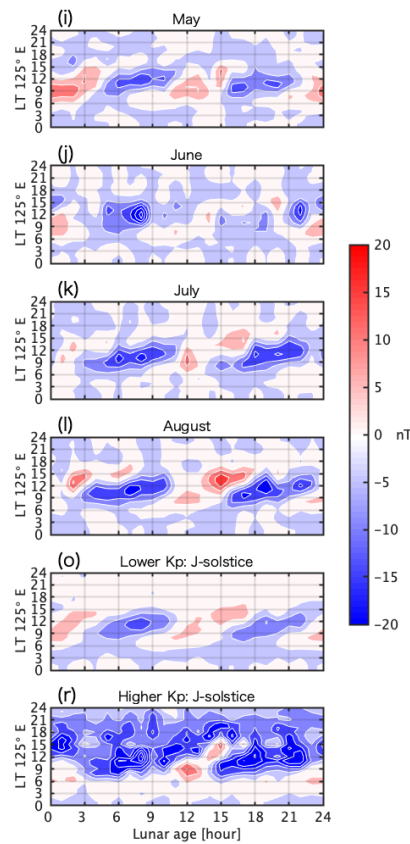

Fig. 4. Seasonal semidiurnal variation for Davao, in same manner of Figure 3.

To demonstrate how the disturbance-time semidiurnal variations differs from the quiettime, Figure 5 is reproduced by Figure $2(\mathrm{~b}, \mathrm{c}, \mathrm{e}, \mathrm{f})$ regarding of the moon age. It is obvious that the disturbance-time semidiurnal variation is modulated by some additional mechanisms. Figure 5 suggests there are two types of $K_{P}$ dependence. One is the modulation due to the moon phase, the other is the moon-phase-non-related modulation.

For the full and new moon phase, afternoon troughs are more amplified during disturbance time than the quiet time. The negative peak of the trough is amplified at 15:00 LT during the full and new moon, while there is no significant decreasing at 09:00 LT during the half moon. The full/new-moon-phase enhanced troughs might be caused by the enhanced westward current resulting from the disturbance dynamo, since the disturbance dynamo could be relatively dominant against the quiet-time ionospheric dynamo in the afternoon. The halfmoon-phase trough, however, is almost same amplitude between the quiet and disturbance time. For the possible reason, the morning ionospheric dynamo current should be strong for the effect of the disturbance dynamo. The difference between Ancon and Davao for the halfmoon phase is caused by the latitudinal dependence on the effect of the disturbance dynamo. The dotdash line shows the morning positive enhancement and the strong depressions after sunset for the moon-phase-non-related modulation. These modulations might be connected with the penetration electric field form pole region to the equatorial region. 


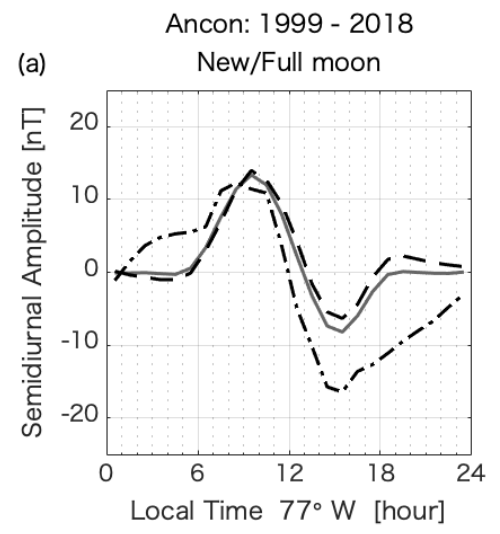

(b)

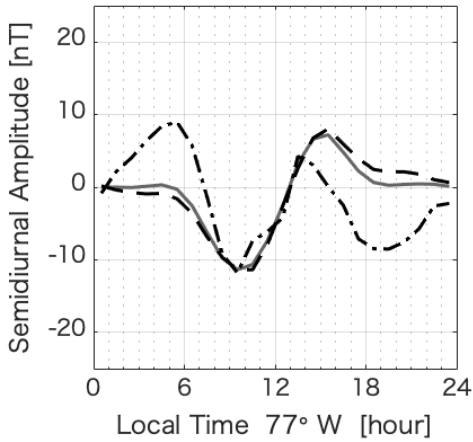

Davao: 1999 - 2018

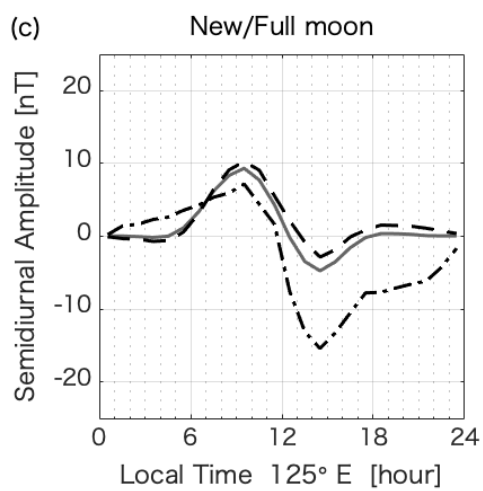

(d)

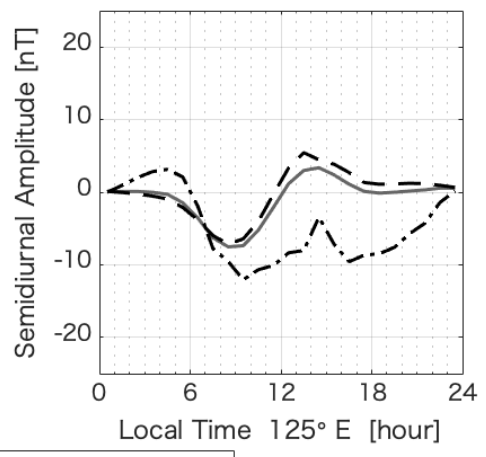

Fig. 5. Semidiurnal amplitude as a function of each local time for Ancon $(a, b)$ and Davao (c, d). The solid line, dash line and dotdash line indicate all data, lower $K_{P}$ and higher $K_{P}$, respectively. The upper panels are new and full moons and the bottoms are half of moons.

\subsection{Seasonal//ongitudinal dependence}

For quiet time, our seasonal dependence of semidiurnal variation agrees with the seasonal profile of atmospheric neutral wind (2.2) mode corresponding to the lunar tide [33]. In other words, the semidiurnal variations in D-solstice and Equinoxes have large amplitudes and Jsolstice is smaller amplitude. The differences between amplitude of Ancon and Davao is resulted from the dependence of the main magnetic field. Yizengaw et al. (2017) [34] showed that the semidiurnal wave amplitude of Davao is stronger than that of Ancon. Our results, however, showed the opposite feature. In addition, their semidiurnal structure is completely different ours. It seems to be reasonable to expect that we could demonstrate more appropriate semidiurnal variation due to the enough analyzed data than Yizengaw et al. (2017): we used the 20-year long-term data, while 5 years for Yizengaw et al. (2017).

Soares et al. (2019) [35] examines that the longitudinal variability of the equatorial counter electrojet (CEJ) during the solar cycle 24 . They show the lunar phase modulation of CEJ and results in the morning CEJ occurrence peak rates around the half of moon and the afternoon CEJ around the new and full moons. The occurrence peak patters are same for all longitudinal sector. For our result, the trough of semidiurnal variations is agreed with the lunar phase modulation of CEJ in Soares et al. (2019). That is, the semidiurnal lunar tidal variation mainly causes the CEJ variability and dominantly modulates the quiet EEJ structure. 
For disturbance time, we need to analyze data more carefully, regarding for the sources of disturbances: CME- or CIR-related storms, substorm activity or Ionospheric irregularities such as the equatorial plasma bubbles, the stratospheric sudden warmings.

\section{Summary}

The analysis of 20-year long-term semidiurnal lunar tidal variations gave the evidence that the semidiurnal variations are completely different between the magnetic quiet and disturbed periods. This is the first time that the seasonal dependence of disturbance-time semidiurnal variation has been provided from the analysis of the EE-index.

1. The $K_{P}$ dependence

- For full and new moon phase, counter troughs are amplified during disturbance time, possibly related to disturbance dynamo.

- For all moon phase, there are positive enhancements in dawn and strong depressions after sunset, resulting from the penetration of polar electric filed.

2. Seasonal dependence

- Semidiurnal variations are divided to three seasonal groups, and characterized as deep trough, enhanced crest and weak structure for D-solstice, Equinoxes and J-solstice, respectively.

- There is no significant longitudinal difference between Ancon and Davao, except for the amplitude of semidiurnal variations.

- The deep troughs occur during D-solstice and the enhanced crests during Equinoxes, at both Ancon and Davao.

\section{Acknowledgement}

The authors are very grateful to MAGDAS for Ancon and Davao magnetometer data. We acknowledge GFZ German Research Centre for Geosciences for providing $K_{P}$ index data. This work is supported by the JSPS KAKENHI (17J40136).

\section{References}

1. Y. Yamazaki, M.J. Kosch, J. Geophys. Res. Space Phys. 119, 6732-6744, doi:10.1002/2014JA020203 (2014)

2. B.G. Fejer, M.E. Olson, J.L. Chau, C. Stolle, H. Lühr, L.P. Goncharenko, K. Yumoto, T. Nagatsuma, J. Geophys. Res. 115, A00G03, doi:10.1029/2010JA015273 (2010)

3. Y. Yamazaki, J. Atmos. Sol.-Terr. Phys. 119, 138-146 (2014)

4. R.J. Stening, J. Geophys. Res, 116(A12), doi:10.1029/2011ja017047 (2011)

5. Y. Yamazaki, A.D. Richmond, K. Yumoto, J. Geophys. Res. Space Phys. 117(A4), doi:10.1029/2012ja017514 (2012)

6. Y. Yamazaki, K. Yumoto, D. McNamara, T. Hirooka, T. Uozumi, K. Kitamura, S. Abe, A. Ikeda, J. Geophys. Res. Space Phys. 117(A3), doi:10.1029/2011ja017453 (2012)

7. T.A. Siddiqui, H. Lühr, C. Stolle, and J. Park, Ann. Geophys. 33(2), 235-243, doi:10.5194/angeo-33-235-2015 (2015)

8. O.S. Bolaji, E.O. Oyeyemi, O.P. Owolabi, Y. Yamazaki, A.B. Rabiu, D. Okoh, A. Fujimoto, C. Amory-Mazaudier, G.K. Seemala, A. Yoshikawa, O.K. Onanuga, J. Geophys. Res. Space Phys. 121(8), 8055-8065, doi:10.1002/2016ja022857 (2016) 
9. O.S. Bolaji, E. O. Oyeyemi, O.E. Jimoh, A. Fujimoto, P.H. Doherty, O.P. Owolabi, J.O. Adeniyi, E.O. Falayi, E. Abe, R.O. Kaka, and A. Kotoye, J. Atmos. Sol.-Terr. Phys. 184, 37-56, doi:10.1016/j.jastp.2019.01.006 (2019)

10. P.N. Mayaud, J. Atmos. Terr. Phys. 39, 1055-1070 (1977)

11. R.T. Marriott, A.D. Richmond, S.V. Venkateswaran, J. Atmos. Sol.-Terr. Phys. 31, 311340 (1979)

12. Y. Yamazaki, K. Yumoto, M. G. Cardinal, B. J. Fraser, P. Hattori, Y. Kakinami, J. Y. Liu, K. J. W. Lynn, R. Marshall, D. McNamara, T. Nagatsuma, V. M. Nikiforov, R. E. Otadoy, M. Ruhimat, B. M. Shevtsov, K. Shiokawa, S. Abe, T. Uozumi, and A. Yoshikawa, J. Geophys. Res. Space Phys. 116(A10), doi:10.1029/2011ja016487 (2011)

13. Y. Yamazaki, C. Stolle, J. Matzka, T. A. Siddiqui, H. Lühr, P. Alken, J. Geophys. Res. Space Phys. 122(12), 12,445-412,463, doi:10.1002/2017ja024601 (2017)

14. S. Matsushita, Geophysical J. R. Ast. Soc. 15(1-2), 109-125, doi:10.1111/j.1365246X.1968.tb05751.x. (2007)

15. R.G. Rastogi, J. Geophys. Res. 79(10), 1503-1512, doi:10.1029/JA079i010p01503 (1974)

16. R.G. Rastogi, Planetary and Space Sci. 21(8), 1355-1365, doi:10.1016/00320633(73)90228-6 (1973)

17. Y. Yamazaki, M.J. Kosch, J. Geophys. Res. Space Phys., 120(3), 2276-2287, doi:10.1002/2014ja020773 (2015)

18. J. Uemoto, T. Maruyama, S. Saito, M. Ishii, R. Yoshimura, Ann. Geophys. 28(2), 449454 (2010)

19. T. Akiyama, A. Yoshikawa, A. Fujimoto, T. Uozumi, Journal of Physics: Conference Series, 1152, doi:10.1088/1742-6596/1152/1/012022 (2019).

20. W.J. Burke, C.Y. Huang, L.C. Gentile, L. Bauer, Ann. Geophys. 22, 3089-3098, https://doi.org/10.5194/angeo-22-3089-2004 (2004)

21. T. Uozumi, K. Yumoto, K. Kitamura, S. Abe, Y. Kakinami, M. Shinohara, A. Yoshikawa, H. Kawano, U. Tamiki, T. Terumasa, D. McNamara, J.K. Ishituka, S.L.G. Dutra, B. Damtie, V. Doumbia, O. Obrou, A.B. Rabiu, I.A. Adimula, M. Othman, M. Fairos, R.E.S. Otadoy, Earth, Planets Sp. 60, 785, doi:10.1186/BF03352828 (2008)

22. A. Fujimoto, T. Uozumi, S. Abe, H. Matsushita, S. Imajo, J.K. Ishitsuka, A. Yoshikawa, Sun and Geosphere 11(1), 37-47 (2016)

23. A. Nishida, J. Geophys. Res. 73(5), 1795-1803, doi:10.1029/JA073i005p01795 (1968)

24. A. Nishida, J. Geophys. Res. 73(17), 5549-5559, doi:10.1029/JA073i017p05549 (1968)

25. M. Blanc, A.D. Richmond, J. Geophys. Res. 85(A4), 1669-1686 (1980)

26. T.J. Fuller-Rowell, G.H. Millward, A.D. Richmond, M.V. Codrescu, J. Atmos. Sol.Terr. Phys. 64, 1383-1391 (2002)

27. M. Le Huy, C. Amory-Mazaudier, Magnetic signature of the ionospheric disturbance dynamo at equatorial latitudes: Ddyn. J. Geophys. Res. 110, A10301, doi:10.1029/2004JA010578 (2005)

28. R.G. Rastogi, V.L. Patel, Effect of interplanetary magnetic field on ionosphere over the magnetic equator. Proc. Indian Acad. Sci. A 82, 121-141 (1975)

29. R.G. Rastogi, Nature 268, 422-424 (1977)

30. R.G. Rastogi, Ann. Geophys. 15, 1309-1315 (1997) 
31. T. Kikuchi, K.K. Hashimoto, T.-I. Kitamura, H. Tachihara, B. Fejer, J. Geophys. Res. 108(A11), 1406, doi:10.1029/2003JA009915 (2003)

32. T. Kikuchi, K.K. Hashimoto, K. Nozaki, J. Geophys. Res. 113, A06214, doi:10.1029/2007JA012628 (2008)

33. J.M. Forbes, X. Zhang, S. Bruinsma, J. Oberheide, J. Geophys. Res. Space Phys. 118, 1788-1801, doi:10.1029/2012JA017962 (2013)

34. E. Yizengaw, B.A. Carter, Ann. Geophys. 35(3), 525-533, doi:10.5194/angeo-35-5252017 (2017)

35. G. Soares, Y. Yamazaki, J. Matzka, K. Pinheiro, C. Stolle, P. Alken, A. Yoshikawa, T. Uozumi, A. Fujimoto, A. Kulkarni, Studia Geophysica et Geodaetica, 63(2), 304-319, doi:10.1007/s11200-018-0286-0 (2019) 